\title{
The Role of Social Capital and Reward Factor in the Success of Crowdfunding Project Fundraising: Case Study of Emerging Market Countries
}

\author{
Nabila Sekar Hapsari, Liyu Adhi Kasari Sulung* \\ Department of Management, Universitas Indonesia, Depok, Indonesia \\ ${ }^{*}$ Corresponding author. Email: liyu.as@gmail.com
}

\begin{abstract}
This study aims to determine the role of social capital and reward factor in the success of crowdfunding project fundraising in emerging markets during the period of January 2017 to February 2019. Using secondary and crosssection data from Kickstarter.com, representing projects from Brazil, Russia, India, China, and South Africa, this research uses Ordinary Least Square as the method of data analysis for the hypothesis testing. Firstly, the results obtained are internal social capital that is described by numbers of comment posted by backers and crowdfunders and reward factor that is described by customized reward have positive and significant effects on the success of crowdfunding project fundraising in emerging markets. Secondly, ownership of Facebook account as the external social capital and ego and community reward as reward factor are proven to have no influence. Lastly, in terms of project features, it is evident that target amount of crowdfunding project influences the success of crowdfunding project fundraising, while project duration has no influence on the success of crowdfunding project fundraising.
\end{abstract}

\section{Keywords: Crowdfunding, Social Capital, Reward Factor, Emerging Market}

\section{INTRODUCTION}

In the era of globalization, the development of ideas and creativity in the business world moves very quickly and dynamically. These ideas are made into reality by entrepreneurs through the creation of various projects. However, entrepreneurs who act as project initiator are often faced with funding constraints (Berger and Udell, 1998).

Funding plays an important role because it supports the growth and development of a project (Bruton et al., 2015). However, there are some difficulties faced by project initiators in obtaining funds (Bruton, Khavul, and Chavez, 2011). Along with the development of the digital world, various innovations begin to emerge in the finance sector. In recent years, the business world has been introduced to a new funding source known as crowdfunding. Through crowdfunding, project initiators, called crowdfunders, can obtain money to fund their projects.

Crowdfunding is a collective project funding method that connects crowdfunders with prospective investors, called backers, through a platform to obtain and invest money in return for certain rewards in the form of products or equity (Mollick, 2014). Crowdfunding is now experiencing a fast-paced growth because of technological advancement and increased of trust from potential backers in the digital world. Backers' trust can be gained by intensive interaction between crowdfunders and backers through crowdfunding platforms. Crowdfunding platforms act as a gathering medium for individuals who share the same value (Butticè, Colombo and Wright, 2017).

In addition, social network accounts owned by crowdfunders that are connected to crowdfunding platforms also become a medium for those parties to interact. Both platforms provide an opportunity for crowdfunders to get a community that is expected to support the sustainability of their projects. The relationship between backers and crowdfunders on crowdfunding platform is a form of internal social capital- whereas the relationships established through crowdfunders' social network is a form of external social capital. Both these social capitals form a network that can influence the success of crowdfunding project fundraising. Therefore, social capital becomes the first 
added value in this research related to the study of crowdfunding.

In addition to social capital, the success of crowdfunding project fundraising is also influenced by reward factor in the form of products, services, or appreciation as promised by crowdfunders because backers can get benefits by funding a project, such as gaining experience in project participation and a form of recognition (Gerber, Hui and Kuo, 2012). Therefore, reward factor is the second added value in this research related to the study of crowdfunding.

In addition to social capital and reward factor, other factors contribute to the success of crowdfunding project fundraising. These factors help to reduce asymmetric information and improve the communication quality between crowdfunders and backers (Wang et al., 2018). Thus, this research also wants to know the influence of project features to the success of crowdfunding project fundraising.

Previous crowdfunding studies focus on the United States and several countries in Europe (Massolution, 2015; Da Cruz, 2017). Apart from being well-known in developed countries, crowdfunding has also grown in emerging market countries, namely Brazil, Russia, India, China, and South Africa (BRICS). Therefore, the authors want to see the influence of social capital, reward factors, and project features in the success of crowdfunding project fundraising in emerging market countries.

\section{LITERATURE REVIEW AND HYPOTHESIS DEVELOPMENT}

\subsection{Reward-Based Crowdfunding}

In recent years, crowdfunding has been attracting investors' attention to invest in platform-based project. The concept of crowdfunding is based on the crowdsourcing method, which uses the crowd as a way to obtain ideas and solutions to achieve business goals (Belleflamme, Lambert and Schwienbacher, 2014). There are four types of crowdfunding platform, namely donation-based crowdfunding, reward-based crowdfunding, loan-based crowdfunding, and equitybased crowdfunding (Belleflamme, Omrani and Peitz, 2013).Reward-based is one of the most developed types of crowdfunding. This type offers physical and nonphysical rewards for backers in non-monetary forms (Mollick, 2014).

Reward-based crowdfunding consists of two funding models: "all or nothing" and "keep it all." In rewardbased crowdfunding that adheres to the "all or nothing" model, the amount of funds collected at the end of project period must reach or exceed the initial target amount so that crowdfunders can collect all the funds obtained from backers. On the platforms using the "keep it all" model, crowdfunders will still get all the funds even though the amount of funds collected at the end of project period does not meet the initial target (Cumming, Leboeuf and Schwienbacher, 2015).

Reward-based crowdfunding has a pre-order concept where crowdfunders are collecting funds and doing marketing activities for pre-purchase products before they are marketed to the external community. The projects usually found on these platforms are those that initiate creative ideas or products. Reward-based crowdfunding enables crowdfunders to collect funds and give back rewards to backers that are tailored to the amount of funds invested (Massolution, 2015).

\subsection{Crowdfunding in Emerging Market Countries}

Table I shows the comparison of crowdfunding in BRICS. It summarizes the cause of emergence of crowdfunding platform, the largest crowdfunding platform, the main type of crowdfunding, the regulation that governs crowdfunding activities, and the types of projects launched on the platform. 
Table I. Crowdfunding in Brazil, Russia, India, and South Africa

\begin{tabular}{|l|l|l|l|l|l|}
\hline & \multicolumn{1}{|c|}{ Brazil } & \multicolumn{1}{|c|}{ Russia } & \multicolumn{1}{|c|}{ India } & \multicolumn{1}{c|}{ China } & \multicolumn{1}{c|}{ South Africa } \\
\hline $\begin{array}{l}\text { The emergence of } \\
\text { crowd-funding }\end{array}$ & $\begin{array}{l}\text { Funding difficulties } \\
\text { faced by startup } \\
\text { companies or small, } \\
\text { medium } \\
\text { ennterprises }\end{array}$ & $\begin{array}{l}\text { Limited access } \\
\text { to obtain funds } \\
\text { for creative } \\
\text { projects }\end{array}$ & $\begin{array}{l}\text { Entreoreneurs are } \\
\text { faced with } \\
\text { funding } \\
\text { constraints for } \\
\text { education projects }\end{array}$ & $\begin{array}{l}\text { Micro, small, and } \\
\text { medium enterprise faced } \\
\text { difficulties in obtaining } \\
\text { funds from government }\end{array}$ & $\begin{array}{l}\text { Difficulties faced by } \\
\text { entrepreneurs in } \\
\text { obtaining funds from } \\
\text { banks }\end{array}$ \\
\hline $\begin{array}{l}\text { Largest crowd- } \\
\text { funding platform }\end{array}$ & Catarse.me & Planeta.ru & Fuel A Dream & Angel-Crunch & StartMe \\
\hline $\begin{array}{l}\text { Main type of crowd- } \\
\text { funding platform }\end{array}$ & Reward-based & Reward-based & Donation-based & Equity-based & Loan-based \\
\hline Project type & $\begin{array}{l}\text { Creative and social } \\
\text { projects }\end{array}$ & $\begin{array}{l}\text { Music and } \\
\text { literature } \\
\text { projects }\end{array}$ & $\begin{array}{l}\text { Social, education, } \\
\text { and humanities } \\
\text { projects }\end{array}$ & $\begin{array}{l}\text { Techno-logy and } \\
\text { creative projects }\end{array}$ & $\begin{array}{l}\text { Music, movie, design, } \\
\text { fashion, and techno- } \\
\text { logy projects }\end{array}$ \\
\hline Regulation & $\begin{array}{l}\text { Russia } \\
\text { Ruling No. 588/17 } \\
\text { by Brazilian } \\
\text { Securities (CVM) }\end{array}$ & $\begin{array}{l}\text { In the process } \\
\text { of being drafted } \\
\text { by legislators }\end{array}$ & $\begin{array}{l}\text { The consultation } \\
\text { paper by } \\
\text { Securities } \\
\text { Exchange Board } \\
\text { of India }\end{array}$ & $\begin{array}{l}\text { Squity crowd-funding } \\
\text { regulation by Securities } \\
\text { Association of China }\end{array}$ & $\begin{array}{l}\text { In the process of being } \\
\text { drafted by African } \\
\text { Crowd-funding } \\
\text { Association }\end{array}$ \\
\hline
\end{tabular}

\subsection{Social Capital}

Social capital is defined as information, trust, and norms contained in social networks (Woolcock, 1998). Coleman (1998) explained that social capital is the form of capital obtained from relationship that exists between individuals. Social capital is created, stored, and used through social networks to provide information and benefits (Javakhadze, Ferris and French, 2015).

In the context of crowdfunding, there are two types of social network. The first is the social network found on crowdfunding platforms. This network is established between crowdfunders and backers because of the interactions that happen on the platforms. Crowdfunders try to build a community on the platform, thus the community formed is a form of internal social capital (Butticè et al., 2017). The second is the social network that is created outside of crowdfunding platforms, namely social networking sites that form the external social capital. Both types of social capital can influence the success of project through the community (Davies and Giovannetti, 2018).

This research used number of comments posted by backers and number of comments posted by crowdfunders as measure of internal social capital. The comment section provided on crowdfunding platforms can be used by backers to find information, ask questions, register complaints, and suggest directions to crowdfunders (Wang et al., 2018). It is also can be used by crowdfunders to reply to backers' comments and provide information or clarification about the project (Zheng et al., 2016). This is useful for increasing backers' satisfaction toward crowdfunding project as well as backers' trust (Gu and Ye, 2014).
According to Xiao et al. (2014) the number of comments influences the success of crowdfunding project fundraising. Bao and Huang (2017) explained that, if there are many comments on a project page, it indicates that many backers are interested in the project and show the potential for project success. Colombo, Franzoni, and Rossi-Lamastra (2015) stated that internal social capital is an important factor to attract backers. Thus, the hypotheses proposed are:

H1a: The number of comments posted by backers has a positive effect on the success of crowdfunding project fundraising.

H1b: The number of comments posted by crowdfunders has a positive effect on the success of crowdfunding project fundraising.

Social capital can also be found in the form of external social capital. External social capital is the result of the relationship between crowdfunders and their families, friends, or colleagues. As a popular social networking site, Facebook is the right tool for reaching out to them. Those parties who are connected with crowdfunders will be exposed to project-related information available on crowdfunders' Facebook account. In addition, the Facebook account contains detailed information about crowdfunders so that it can improve the project quality and information reliability (Kim, Hong Por and Yang, 2017). Mollick (2014) stated that the success of crowdfunding project fundraising is influenced by external social capital in the form of Facebook account ownership and the number of friends on the account. Therefore, based on previous study, the hypothesis proposed is: 
H2: The ownership of Facebook account has a positive effect on the success of crowdfunding project fundraising.

\subsection{Reward Factor}

Crowdfunders utilize crowdfunding platforms to raise funds, while backers utilize crowdfunding platform to seek rewards from investment activities (Gerber, Hui and Kuo, 2012). In reward-based crowdfunding, crowdfunders offer a variety of alternative rewards that are tailored to the amount of funds invested by backers. Backers who decide to contribute to a project will get rewards in the form of products, services, or appreciation, as promised by crowdfunders. Therefore, reward is one of the important factors that motivate backers to invest in crowdfunding project (Kuppuswamy and Bayus, 2015). There are three components that can be found in the rewards offered by crowdfunders: customization, ego, and community (Butticè, Colombo and Wright, 2017). Colombo et al. (2015) explained that, in reward-based crowdfunding, rewards that includes customization, ego, and/or community could attract backers to invest.

Customized reward can provide backers the additional benefits that consumers do not obtain in general. This would allow backers to get rewards that match their characteristics and can be adjusted to their preferences. It can also be stored in the form of tangible product. Bao and Huang (2017) explained that customized reward significantly influences the success of crowdfunding project fundraising. Therefore, based on previous study, the hypothesis proposed is:

H3a: Customized reward has a positive effect on the success of crowdfunding project fundraising.

Ego reward is explained as reward that involves public display where backers are positioned as cocreators of a project. This means that the reward offered has the ability to encourage the intrinsic motivation of backers to invest. Bao and Huang (2017) explained that ego reward has a positive effect on the success of crowdfunding project fundraising. Therefore, based on previous research, the hypothesis proposed is:

H3b: Ego reward has a positive effect on the success of crowdfunding project fundraising.

Community reward can be used as a signal from crowdfunders to backers to show certain values that are shared or owned by a project (Zheng et al., 2014). Community reward will give backers the impression that they are members of a project and have the opportunity to learn and share the knowledge they have about business with other backers and also with crowdfunders (Bao and Huang, 2017). This reward can provide backers the opportunity to make new friends who have the same interest (Bao and Huang, 2017).
Thus, based on previous research, the hypothesis proposed is:

H3c: Community reward has a positive effect on the success of crowdfunding project fundraising.

\section{RESEARCH METHOD}

\subsection{Data and Sample}

This study uses secondary and cross-section data during the period from January 2017 to February 2019 from Kickstarter.com. The reasons for choosing Kickstarter are data availability, ease of access, and it is the largest crowdfunding platform. The sampling method used is a non-random or purposive sampling technique. The number of samples among countries will differ because of the project's population in each country. The number of samples used is 197 projects that have met the criteria established by the author. The sample numbers are 14, 34, 40, 93, and 16 for Brazil, Russia, India, China, and South Africa, , respectively.

\subsection{Research Model}

The research model is as follows:

$\mathrm{PG}_{\mathrm{rat}, \mathrm{i}}=\beta_{0}+\beta_{1} \mathrm{CB}_{\mathrm{i}}+\beta_{2} \mathrm{CC}_{\mathrm{i}}+\beta_{3} \mathrm{DFB}_{\mathrm{i}}+\beta_{4} \mathrm{DCust}_{\mathrm{i}}+$ $\beta_{5} \mathrm{DEgo}_{\mathrm{i}}+\beta_{6} \mathrm{DCom}_{\mathrm{i}}+\beta \chi_{\mathrm{i}}+\varepsilon_{\mathrm{i}}(1)$

where:

$\mathrm{PG}_{\mathrm{rat}, \mathrm{i}: \mathrm{:}}$ ratio of pledge per goal amount;

CB-: comments posted by backers;

CC-: comments posted by crowdfunders;

DFB-: Facebook account ownership (dummy);

DCust-: customized reward (dummy);

DEgo-: ego reward (dummy);

DCom-: community reward (dummy); and $\chi$ : control variables.

Thus, the framework of the research is as follows: 


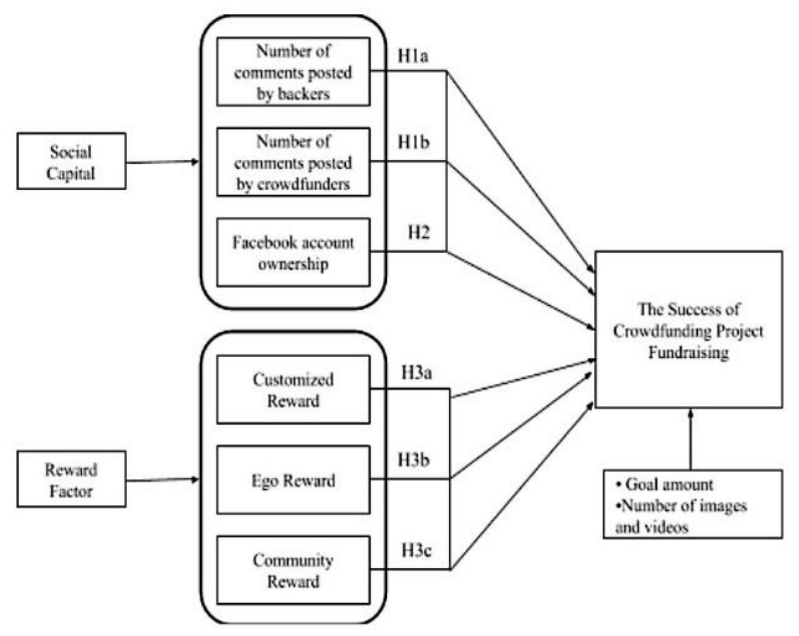

Figure 1 Theoretical Framework

Based on the framework, this research aims to know the role of social capital and reward factor in the success of crowdfunding project fundraising in emerging market countries.

\subsection{Operationalization of Variables}

\subsubsection{Success of Crowdfunding Project Fundraising}

The success of crowdfunding project fundraising is defined by the log ratio of pledge per goal amount of a project. This measure is widely used in previous studies and is transformed into a log form (Scheaf et al., 2018).

\subsubsection{Internal Social Capital}

This research used number of comments posted by backers and number of comments posted by crowdfunders as measure of internal social capital (Kim, Hong Por and Yang, 2017). This measurement is gained from the comment section of the Kickstarter platform.

\subsubsection{External Social Capital}

The external social capital is defined by the ownership of Facebook account. It is in the form of dummy variable of 0 or 1 (Mollick, 2014).

\subsubsection{Reward Factor}

The reward factor is consisting of customized reward, ego reward, and community reward, which explain the form of reward that is given to backers from crowdfunders of a project (Bao and Huang, 2017).

\subsubsection{Control Variables}

The control variables include the number of images and videos as well as the goal amount of a project.

\section{RESULTS AND DISCUSSION}

\subsection{Statistic Descriptive}

Table II depicts the descriptive statistical analysis results that consist of mean value, minimum value, maximum value, standard deviation, and number of observations in this research. Based on Table II, on average, the 197 crowdfunding projects can achieve $67.41 \%$ of their actual target. In terms of internal social capital, the average number of comments posted by backers almost reached 377 with the least amount of zero, which means there is no comment found on the project page. A technology project named "Atom, World's Smallest 4G Rugged Smartphone" from China has the most comments posted by backers, reaching 6799. The number of comments posted by crowdfunders almost reached 86 comments with the least amount of zero. The project with the most comments posted by crowdfunders is from China named "LattePanda Alpha A Tiny Beastly Windows Device!" with 1174 comments found on the project page. In terms of external social capital, the $46.19 \%$ of projects linked crowdfunders' Facebook account to the project page.

In terms of reward factor, $46.19 \%$ of projects posted customized rewards, $52.28 \%$ posted ego rewards and 49.24\% community rewards. There are two control variables: target amount and number of photos and videos. Target amount has nominal values ranging from USD 23 to thousands of USD, thus the variable is transformed into log form. Based on Table II, the average target amount of crowdfunding project is 8.70 , while the maximum value is 13.12 and the minimum value is 3.14. The number of photos and videos found on project page has an average value of 22 . The highest number of photos and videos is 95 and the lowest value is 0 , which means there are no photos, or videos found on project page. 
Table II. Descriptive Statistics

\begin{tabular}{|c|c|c|c|c|c|c|c|c|c|}
\hline & PG & CB & CC & DFB & DCust & DEgo & DCom & $\begin{array}{c}X_{\mathrm{i}} \text { (No. of } \\
\text { Photos and } \\
\text { Videos) }\end{array}$ & $\begin{array}{c}\mathrm{X}_{\mathrm{i}} \text { (Goal } \\
\text { Amount) }\end{array}$ \\
\hline Mean & 0.6741 & 376.94 & 85.974 & 0.4619 & 0.4619 & 0.5228 & 0.4924 & 8.7001 & 21.888 \\
\hline Maximum & 4.7098 & 6799.00 & 1174.00 & 1 & 1 & 1 & 1 & 13.122 & 95 \\
\hline Minimum & 0 & 0 & 0 & 0 & 0 & 0 & 0 & 3.1355 & 0 \\
\hline Std. Dev. & 0.9417 & 1040.027 & 163.6016 & 0.4998 & 0.4998 & 0.5008 & 0.5012 & 1.6569 & 19.165 \\
\hline Obs. Total & 197 & 197 & 197 & 197 & 197 & 197 & 197 & 197 & 197 \\
\hline
\end{tabular}

\subsection{Classic Assumption Test}

The classic assumption tests in this research include multicollinearity and heteroskedasticity test. Based on Table III, the results from the multicollinearity test using variance inflation factor (VIF) has an average value of 1.47, which indicates that there is no multicollinearity problem because the value is under 10 (Brooks, 2008). Based on the test results in Table IV, it appears that the probability of chi-square is equal to 0.0000 , which means that the null hypothesis is rejected, thus it can be concluded that the variance is not constant, i.e., there is a heteroskedasticity problem in the model (Brooks, 2008).
Table III. Output from Multicollinearity Test Using VIF

\begin{tabular}{|c|c|}
\hline Variables & $\begin{array}{c}\text { Variance } \\
\text { Inflation Factor } \\
\text { (VIF) }\end{array}$ \\
\hline Number of comments posted by backers & 1.75 \\
\hline Number of comments posted by crowdfunders & 1.74 \\
\hline Facebook account ownership & 1.07 \\
\hline Customized reward & 1.30 \\
\hline Ego reward & 1.36 \\
\hline Community reward & 1.38 \\
\hline Log of target amount & 1.56 \\
\hline Number of photos and videos & 1.59 \\
\hline Mean VIF & $\mathbf{1 . 4 7}$ \\
\hline
\end{tabular}

Table IV. Output from Heteroskedasticity

\begin{tabular}{|c|c|}
\hline \multicolumn{2}{|c|}{ Breusch-Pagan/Cook-Weisberg test for Heteroskedasticity } \\
\hline chi2(1) & 95.10 \\
\hline Prob > chi2 & 0.0000 \\
\hline
\end{tabular}

\subsection{Regression Result}

Table V. Model Regression Result

\begin{tabular}{|c|c|c|c|c|c|c|c|c|c|c|c|c|}
\hline & \multicolumn{3}{|c|}{ Model 1} & \multicolumn{3}{|c|}{ Model 2} & \multicolumn{3}{|c|}{ Model 3} & \multicolumn{3}{|c|}{ Model 4} \\
\hline & Sign & Coef. & T-Stat & Sign & Coef. & T-Stat & Sign & Coef. & T-Stat & Sign & Coef. & T-Stat \\
\hline $\begin{array}{l}\text { Number of } \\
\text { comments posted } \\
\text { by backers }\end{array}$ & & & & + & $\begin{array}{l}0.00029 \\
6 * * *\end{array}$ & 2.95 & & & & + & $\begin{array}{l}0.0002 \\
78 * * *\end{array}$ & 2.97 \\
\hline $\begin{array}{l}\text { Number of } \\
\text { comments posted } \\
\text { by crowdfunders }\end{array}$ & & & & + & $\begin{array}{l}0.00133 \\
* *\end{array}$ & 1.98 & & & & + & $\begin{array}{l}0.0011 \\
9^{*}\end{array}$ & 1.75 \\
\hline $\begin{array}{l}\text { Facebook account } \\
\text { ownership }\end{array}$ & & & & + & 0.01437 & 0.13 & & & & + & 0.0301 & 0.27 \\
\hline $\begin{array}{l}\text { Customized } \\
\text { reward }\end{array}$ & & & & & & & + & $\begin{array}{l}0.368 * \\
* *\end{array}$ & 2.91 & + & $\begin{array}{l}0.283 * \\
* *\end{array}$ & 2.57 \\
\hline Ego reward & & & & & & & - & 0.142 & -0.98 & - & 0.0276 & -0.22 \\
\hline $\begin{array}{l}\text { Community } \\
\text { reward }\end{array}$ & & & & & & & - & 0.119 & -0.76 & - & 0.086 & -0.70 \\
\hline $\begin{array}{l}\text { Log of target } \\
\text { amount }\end{array}$ & - & $\begin{array}{l}0.153 \\
* * *\end{array}$ & -3.23 & - & $\begin{array}{l}0.206^{* *} \\
*\end{array}$ & -4.85 & - & $\begin{array}{l}0.117 * \\
*\end{array}$ & -2.47 & - & $\begin{array}{l}0.181 * \\
* *\end{array}$ & -4.11 \\
\hline $\begin{array}{l}\text { Number of photos } \\
\text { and videos }\end{array}$ & + & $\begin{array}{l}0.025 \\
* * *\end{array}$ & 5.28 & + & $\begin{array}{l}0.0184 * \\
* *\end{array}$ & 3.48 & + & $\begin{array}{l}0.0222 \\
* * *\end{array}$ & 4.62 & + & $\begin{array}{l}0.0169 \\
* * *\end{array}$ & 3.27 \\
\hline
\end{tabular}


Based on Table $\mathrm{V}$, we can see that internal social capital that is represented by the number of comments posted by backers has a significant influence on the success of crowdfunding project fundraising. With the tstatistic value shown in Models 2 and 4 that exceeds the t-table value, which is equal to $1.65,1.96$, and 2.58 for confidence level of $10 \%, 5 \%$, and $1 \%$, respectively, it can be concluded that Hypothesis 1a is accepted. Kim et al (2017) explained that crowdfunding projects with more comments have a greater chance of success in raising funds. Therefore, the results for the number of comments posted by backers are aligned with previous study. Comments containing questions, complaints, and suggestions posted by backers can reduce information gap between backers and crowdfunders. This is useful for dealing with issues related to trust of backers (Kim, Hong Por and Yang, 2017). It will have a positive impact on the project quality (Mollick, 2014).

In addition, internal social capital that is also represented by the number of comments posted by crowdfunders has a significant influence on the success of crowdfunding project fundraising. With the t-statistic value shown in Models 2 and 4, it can be concluded that Hypothesis $1 \mathrm{~b}$ is accepted at confidence level of $10 \%$. Colombo et al (2015) explained that internal social capital is an important factor in attracting backers. It is also explained by Kim et al (2017) and Wang et al (2018), who stated that more comments found on the project page increased the probability of successful project fundraising. Comments posted by crowdfunders can provide additional information, answer backers' questions, and provide clarifications about the project details. This is useful for increasing backers' satisfaction toward crowdfunding projects, thus it can drive the success of fundraising (Gerber, Hui and Kuo, 2012).

The external social capital as defined by Facebook account ownership, does not significantly influences the success of crowdfunding project fundraising. The tstatistics shows the values that are smaller than the ttable value in Models 2 and 4 at the confidence levels of $10 \%, 5 \%$, and $1 \%$. Therefore, Hypothesis 2 is rejected. Mollick (2014) stated that project success is influenced by external social capital in the form of account ownership and number of friends on Facebook account. In addition, the use of social networking is an important factor that can affect the amount of funds collected and the number of backers investing. However, in this study, Facebook account ownership does not increase the success of crowdfunding project fundraising. Therefore, the result of this study does not align with prior studies.

In Table V, we can see that the reward factor that is represented by customized reward has a significant influence on the success of crowdfunding project fundraising. In Models 3 and 4, it has t-statistic values that exceed the t-table value and it also has positive coefficients. With these values, it can be concluded that Hypothesis 3a is accepted. Butticè et al (2017) stated that customized reward has positive effect on crowdfunding project performance, which was supported by Bao and Huang (2017), who explained that customized reward significantly influences the success of crowdfunding project fundraising, thus the result of this research is aligned with prior studies. Customized reward would allow backers to get the reward that match their characteristics and preferences (Bao and Huang, 2017).

Based on Table $\mathrm{V}$, ego reward does not have a significant influence on the success of crowdfunding project fundraising. The t-statistic in Models 3 and 4 has a value that is smaller than the t-table value. Thus, it can be concluded that Hypothesis $3 \mathrm{~b}$ is rejected. Ego reward is explained as the involvement of backers in crowdfunding project that is shown through public display where backers are positioned as co-creators. It means that the rewards offered can encourage backers' intrinsic motivation to invest (Bao and Huang, 2017). Bao and Huang (2017) explained that ego reward has a positive effect on the success of crowdfunding projects, but the result of this research is different from prior study. Based on Models 3 and 4 in Table V, community reward has a t-statistic value that is smaller than t-table value at confidence level of $10 \%, 5 \%$, and $1 \%$. Thus, it can be concluded that community reward does not have a significant influence on the success of crowdfunding project fundraising. Therefore, Hypothesis $3 \mathrm{c}$ is rejected. Bao and Huang (2017) stated that community reward has a positive effect in the success of crowdfunding project fundraising. However, this research shows a different result.

\subsection{Robustness Check}

Two independent variables are added to the model to see the robustness of regression results. The authors added project duration and number of projects backed by crowdfunders as additional variables. The robustness check shows the results of significance that are consistent with Table V. Based on the results, project duration does not have a significant effect on the success of crowdfunding project fundraising. It is aligned with a previous study by Colombo et al (2015). The number of projects backed by crowdfunders is negatively significant on the success of crowdfunding project fundraising at the $5 \%$ confidence level. Therefore, it can be concluded that the results of robustness check is consistently significant and aligned with the results in Table V.

\section{CONCLUSIONS AND IMPLICATION}

Internal social capital, as defined by the number of comments posted by backers and the number of 
comments posted by crowdfunders, is positively proven to influence the success of crowdfunding project fundraising in emerging markets. Firstly, the number of comments posted by backers can indicate the number of backers who are interested in the project. It also contributes by giving additional information to prospective backers. Secondly, the number of comments posted by the crowdfunders can provide additional information about the project and explain more details about the questions asked by backers, while external social capital, as defined by the ownership of Facebook accounts, does not significantly influence the success of crowdfunding project fundraising in emerging markets. It can be caused by the large number of crowdfunders who do not link their Facebook account to the project page.

The reward factor is explained by three components: customized reward, ego reward, and community reward. Customized reward is proven to have a significant effect on the success of crowdfunding project fundraising, because it allows backers to get reward with certain characteristics that can be adjusted based on their preferences. Ego reward and community reward have no significant effect on the success of crowdfunding project fundraising, which might be due to the data being spread across 15 categories of projects on Kickstarter.com such that the reward offered might be varied and/or cannot be compared to one and another.

\section{RESEARCH LIMITATIONS}

This study uses the reward-based crowdfunding as a sample and the data used are only from projects created between 2017 and 2019. It is due to the limited time of data collection, thus the sample quantity was also very limited. The use of donation-based, loan-based, or equity-based crowdfunding as samples may show different results, because, in addition to the different kinds of platform, it may capture other variables as the factor of crowdfunding project's success. Suggested further research should categorize the project based on the range of the goal amount.

\section{REFERENCES}

[1] Bao, Z., and Huang, T., (2017). 'External supports in reward-based crowdfunding campaigns: A comparative study focused on cultural and creative projects', Online Information Review, 41(5), pp. 626-642.

[2] Belleflamme, P., Lambert, T., and Schwienbacher, A., (2014). 'Tapping the right crowd', Journal of Business Venturing, 29, pp. 585-609.

[3] Belleflamme, P., Omrani, N., and Peitz, M.,(2013). 'The economics of crowdfunding platform', Center for Operation Research and Econometrics, 33.
[4] Berger, A. N. and Udell, G. F., (1998). 'The economics of small business finance: The roles of private equity and debt markets in the financial growth cycle', Journal of Banking and Finance, 22(6), pp. 613-673.

[5] Brooks, C., (2008). 'Introductory Econometrics for Finance, ' Cambridge University Press, UK.

[6] Bruton, G., Khavul, S., and Chavez, H., (2011). 'Microlending in emerging economies: Building a new line of inquiry from the ground up; Journal of International Business Studies, 42.

[7] Bruton, G., Khavul, S., Siegel, D., and Wright, M., (2015). 'New financial alternatives in seeding entrepreneurship: Microfinance, crowdfunding, and peer-to-peer innovations', Entrepreneurship: Theory and Practice, 39(1), pp. 9-26.

[8] Butticè, V., Colombo, M. G., and Wright, M.; (2017). 'Serial crowdfunding, social capital, and project success', Entrepreneurship: Theory and Practice, 41 (2), pp. 183-207.

[9] Coleman, J., (1998). 'Social capital in the creation of human capital', American Journal of Sociology, 94, S95-S120.

[10] Colombo, M. G., Franzoni, C., and RossiLamastra, C., (2015). 'Internal social capital and the attraction of early contributions in crowdfunding', Entrepreneurship: Theory and Practice.

[11] Cumming, D. J., Leboeuf, G., and Schwienbacher, A., (2014). 'Crowdfunding models: Keep-it-all vs all-or-nothing',pp. 1-37.

[12] Da Cruz, J. V., (2017). 'The economics of crowdfunding: Entrepreneurs' and Platforms' Strategies'..

[13] Davies, W. E., and Giovannetti, E., (2018). 'Signalling experience and reciprocity to temper asymmetric information in crowdfunding evidence from 10,000 projects', Technological Forecasting and Social Change, 133 (C), pp. 118-131.

[14] Gerber, E., Hui, J., and Kuo, P.-Y.,(2012). 'Crowdfunding: Why people are motivated to post and fund projects on crowdfunding platforms', Computer Supported Cooperative Work, 2.

[15] Gu, B. and Ye, Q. (2014). First step in social media: Measuring the influence of online management responses on customer satisfaction. Production and Operations Management, 23 (4), 570-582. 
[16] Javakhadze, D., Ferris, S., and French, D., (2015). 'Social capital, investments, and external financing', Journal of Corporate Finance, 37.

[17] Kim, T., Hong Por, M., and Yang, S.-B., (2017). 'Winning the crowd in online fundraising platforms: The roles of founder and project features', Electronic Commerce Research and Application.

[18] Kuppuswamy, V., and Bayus, B., (2013). 'Crowdfunding creative ideas: The dynamics of project backers in kickstarter'.

[19] Massolution,. (2015) 'The crowdfunding industry report'.

[20] Mollick, E., (2014). 'The dynamics of crowdfunding: An exploratory study', Journal of Business Venturing, 29.

[21] Scheaf, D. J., Davis, B. C., Webb, J. W., Coombs, J. E., Borns, J., and Holloway, G. (2018). 'Signals' flexibility and interaction with visual cues: Insights from crowdfunding', Journal of Business Venturing 33 (6), pp. 720-741.
[22] Wang, N., Li, Q., Liang, H., Ye, T., and Ge, S., (2018). 'Understanding the importance of interaction between creators and backers in crowdfunding success', Electronic Commerce Research and Application, 27.

[23] Woolcock, M., (1998). 'Social capital and economic development: Toward a theoretical synthesis and policy framework', Theory and Society, 27 (2), pp. 151-208.

[24] Xiao, S., Tan, X., Dong, M., and Qi, J., (2014). 'How to design your project in the online crowdfunding market? Evidence from Kickstarter'.

[25] Zheng, H., Hung, J.-L., Xu, B., and Qi, Z., (2016). 'The role of trust management in reward-based crowdfunding', Online Information Review, 40 (1), pp. 97118.

[26] Zheng, H., Li, D., Wu, J., and Xu, Y., (2014). 'The role of multidimensional social capital in crowdfunding: A comparative study in China and US', Information \& Management, 51. 